\title{
Simplified Individual Oral Health Index Estimated by Use of Excel Program
}

\author{
Seung-Chul Shin \\ Department of Preventive Dentistry, Dankook University, Korea
}

It would be very important to calculate the individual oral health index for estimating the relative oral health level in order to make the individual preventive planning according to the oral health level by comparing with other's level. It has not been developed the individual oral health level index in general, on the other hands, well developed and widely used the general body health index such as skin age, bony age, mental age, muscle age or the specific organ health index, to estimate the patient specific organ health level to compare with others.

5 basic factors as the natural teeth state, caries state, periodontal state, other oral condition and systemic body condition or the oral health habit were considered to estimate the individual oral health level, considering with the different weight of each factor, calculated from the regression analysis, according to the 6 age groups as preschool age, school child, adolescent, young adult, prime of manhood and aged person.

Excel computer program would be useful to estimate the individual oral health level as adding the points for each item related with the oral health by age group, with easy and simple. The result of the individual oral health index would be suggested as 5 degrees as very good as A level, good for B level, Moderate as C group, poor as D group and very poor as E group, and a little different preventive planning would be suggested according to the individual oral health level, as available to use for recall system for preventive dental cares clinically.

Key words: oral health, preventive dental care, recall system, caries prevention

Copyright (C) 2021. Korean Academy of Preventive Dentistry. All rights reserved.

This is an Open Access article distributed under the terms of the Creative Commons Attribution Non-Commercial License (http://creativecommons.org/licenses/ by-nc/4.0) which permits unrestricted non-commercial use, distribution, and reproduction in any medium, provided the original work is properly cited. 